\title{
I Am Feeling Back to Those Days: The Three- Way Interaction Effect of Nostalgia, Age, and Gender on Youthfulness in Nostalgia Advertising: An Abstract
}

\author{
Young K. Kim and Mark Y. Yim
}

\begin{abstract}
Although the extant literature on nostalgia's positive effects might support the belief that it is an effective marketing communication strategy, it is unreasonable to predict that its effectiveness can be generalized to nearly all consumers. Two studies are conducted in a different context to test how each group of consumers by age and gender responds to nostalgic feelings. Study 1 manipulates nostalgia through narrative writing tasks, and Study 2 replicates it through experimentergenerated print ads. The results across two studies consistently reveal a significant three-way interaction effect of nostalgia, age, and gender on consumers' perceived youthfulness. Specifically, older women tend to feel less youthful than older men when nostalgic feelings are induced. Our mediated moderation analysis shows that these differences in older adults' perceived youthfulness are due to self-discrepancy between current and ideal body image. Furthermore, we identify that nostalgic feelings in advertising benefit as a marketing communication strategy because they generate positive emotions initiated by youthfulness, resulting in positive attitudes toward the ad. The theoretical and practical implications of these findings are discussed, and future research directions are offered.
\end{abstract}

References Available Upon Request

\author{
Y.K. Kim $(\bowtie)$ \\ University of Iowa, Iowa City, IA, USA \\ e-mail: youngkyu-kim@uiowa.edu \\ M.Y. Yim \\ University of Massachusetts Lowell, Lowell, MA, USA \\ e-mail: mark_yim@uml.edu
}

